\title{
Tribological behavior of Clutch Plate Material in Laboratory Simulated Conditions
}

\author{
Pravin B Bhorkade ${ }^{1}$ \\ ${ }^{1}$ P.G Student (Mechanical Design Engineering) \\ Department of Mechanical Engineering \\ NDMVP'S KBT COE, Nashik, \\ Pune University, Pune, Maharashtra, India
}

\begin{abstract}
A Clutch is a machine member used to connect the driving shaft to a driven shaft, so that the driven shaft may be started or stopped at will, without stopping the driving shaft. While riding the clutch, it simply means keeping the clutch pedal, fully, or partially pressed down. Hence, the pressure on the pad is creating a huge amount of friction which will very quickly produces the wearing in Clutch plate material. The concept is to understand material behavior and wear and friction criteria. The clutch plate is made of material usually of Grey Cast Iron with Asbestos used as Friction Lining Material. In this research, an attempt is made to try out Composite material clutch plate. Composite are of polymer, ceramic and metal matrix type. The use of composites is motivated because of good friction co-efficient and wear resistant properties. The aim of this present work is to identify a heat resistant clutch material for optimum friction coefficient $(\mu)$ and to decide a perfect composite material which has low wear rate at different temperature, load and velocity conditions. The Clutch Plate is modelled and analyzed using Creo and FEA software. The Experimental investigation of plate is done by Pin on Disc Apparatus for validation of wear rate and Friction Co-efficient.
\end{abstract}

Key words: Clutch Plate, Wear Rate Analysis, Pin on Disc Setup.

\section{INTRODUCTION}

Wear is damage to a surface as a result of relative motion with respect to another substance. One key point is that wear is damage and it is not limited to loss of material from the surface. However, loss of material is definitely one way in which apart can experience wear. In the older definitions of wear there used to be a greater stress on the "loss of material"

Wear causes an enormous annual expenditure by industry and consumers. For some industries such as agriculture, as many as $40 \%$ of the components replaced on equipment's have failed by wear. Estimates of direct cost of wear to industrial nations vary from $1 \%$ to $4 \%$ of GNP and it is estimated that $10 \%$ of all energy generated by man is dissipated in various friction processes. Thus the magnitude of losses caused to mankind (which can be expressed in percentage points of GDP) makes it absolutely

necessary to study ways to minimize it. Thus minimizing wear, affects the economics of production in a major way

A clutch mainly consists of two parts, i.e. friction plates and separator plates. These plates engage and disengage to transmit speed and torque. The transmitted torque is proportional to the overall friction coefficient of the clutch plates. The friction behavior of clutch plates is critical for overall performance of the transmission and it depends on the

\author{
Dr. A. B. Kakade ${ }^{2}$ \\ ${ }^{2}$ Professor, Department of Mechanical Engineering \\ NDMVP'S KBT COE,Nashik, Maharashtra, India. \\ Savitribai Phule Pune University, Pune, Maharashtra, India.
}

sliding velocity, the normal pressure, the lubrication, the temperature and the surface topography of the clutch plates. It is necessary to investigate the effect of surface topography on the friction behavior of the clutch plates. Study of various research paper, the surface characteristics of clutch plate materials have been investigated since it is closely related to friction[1]. describes Engagement characteristics of a friction pad for commercial vehicle clutch system[2]. analyze the effect of different material composition on friction \& wear of Clutch Plate material[3]. the effect of load, Velocity of sliding and sliding distance on friction and wear of materials made of Polytetrafluoroethylele (PTFE) and PTFE composites[11].

In the present work the wear behavior of various clutch materials at different operating conditions is carried out using pin on disc apparatus. Additionally, the wear volume is calculated and hardness was carried out. Further finite element analysis of clutch plate was carried out.

\section{EXPERIMENTAL DETAILS}

Wear is a process of removal of material from one or both of two solid surfaces in solid state contact. As the wear is a surface removal phenomenon and occurs mostly at outer surfaces, it is more appropriate and economical to make surface modification of existing alloys than using the wear resistant alloys.[1]

Pin on disk wear testing is a method of characterizing the coefficient of friction, frictional force and rate of wear between two materials. As a particularly versatile method for testing wear resistance, pin on disk can be configured in multiple scenarios depending on the goals of your project.

Pin on disk testing can simulate multiple wear modes, including unidirectional, bidirectional, omnidirectional and quasi-rotational wear. Our equipment allows us to test virtually any combination of materials to determine the effect of wear on a medical device.[3]

In this experiment, the test was conducted with the following parameters:

1. Load

2. $\quad$ Speed

3. Distance

TABLE 6 SPECIFICATIONS OF SETUP

\begin{tabular}{|l|l|}
\hline \multicolumn{1}{|c|}{ Parameters } & \multicolumn{1}{c|}{ Values } \\
\hline Specimen pinsize & Dia $12 \mathrm{~mm} \mathrm{\&} \mathrm{30mm} \mathrm{height}$ \\
\hline Wear Disc Size & Dia. $165 \mathrm{~mm}, 8 \mathrm{~mm}$ thick \\
\hline Disc rotation & $1000 \mathrm{rpm}$ \\
\hline Sliding speed & 0.5 to $10 \mathrm{~m} / \mathrm{s}$ \\
\hline Normal load & $5 \mathrm{~N}$ to $200 \mathrm{~N}$, In steps of $5 \mathrm{~N}$ \\
\hline
\end{tabular}




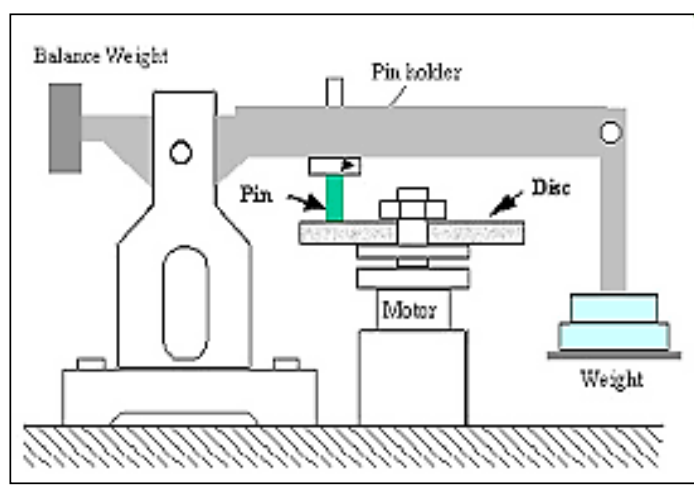

Figure 2 Pin on Disk Setup

- Pressure plate:-

The Pressure plate is generally made from grey cast iron (FG $300)$. Because of its high heat and wear resistant but its cost is too high.

In this Experiment use Pressure plate Grey Cast iron Material properties \& Chemical composition given Below.[2]

\section{TABLE 1 MATERIAL PROPERTIES OF GREY CAST IRON}

\begin{tabular}{|c|c|}
\hline Material and Properties & Value \\
\hline Ultimate Tensile Strength (MPa) & 1015 \\
\hline Ultimate Yield Strength (MPa) & 979 \\
\hline Young's Modulus (MPa) & $2 \mathrm{e}^{5}$ \\
\hline Poisson's Ratio & 0.29 \\
\hline Density (kg/m $\left.{ }^{3}\right)$ & 7850 \\
\hline Elongation (\%) [EL] & $<1$ \\
\hline Hardness (BHN) & 160 to 210 \\
\hline Crack growth resistance (MPa m) & $11-19$ \\
\hline
\end{tabular}

TABLE 2 CHEMICAL COMPOSITION OF GREY CAST IRON

\begin{tabular}{|c|c|c|}
\hline No. & Material & Composition \\
\hline 1 & Carbon & $0.4 \%$ \\
\hline 2 & Silicon & $1.1 \%$ \\
\hline 3 & Phosphorus & $0.68 \%$ \\
\hline 4 & Manganese & $4.2 \%$ \\
\hline 5 & Copper & $0.5 \%$ \\
\hline 6 & Chromium & $0.07 \%$ \\
\hline 7 & Nickel & $0.02 \%$ \\
\hline 8 & Molybdenum & $0.007 \%$ \\
\hline
\end{tabular}

- Materials :-

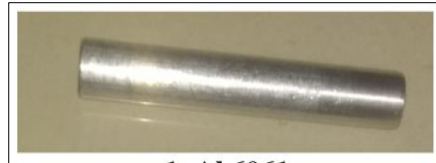

1. Al 6061

3. Carbon Fiber

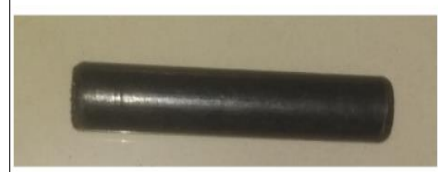

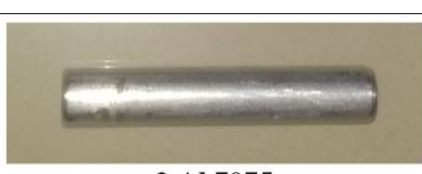

2.Al 7075

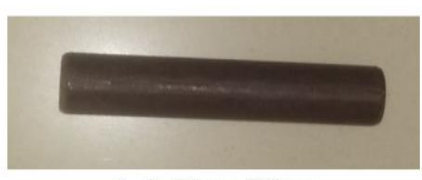

4. S-Glass Fiber
Figure 1. Specimen Sample of Different Pins
- Al6061:

It has Good Strength in terms if Impact, Fatigue and Shearing. Good Machinability and Weldablity. The material can be casted into desired shape and hence good actability. Good Corrosion resistant to corrosive environment. Good surface finish and wear resistant

TABLE 3 CHEMICAL COMPOSITION OF AL6061

\begin{tabular}{|c|l|c|}
\hline No. & \multicolumn{1}{|c|}{ Material } & Composition \\
\hline 1 & Aluminium $\mathrm{Al}$ & $90.2499-94.9999$ \\
\hline 2 & Copper $\mathrm{Cu}$ & $3.9-5.0$ \\
\hline 3 & Silicon $\mathrm{Si}$ & $0.5-1.2$ \\
\hline 4 & Manganese $\mathrm{Mn}$ & $0.4-1.2$ \\
\hline 5 & Magnesium $\mathrm{Mg}$ & $0.2-0.8$ \\
\hline 6 & Iron $\mathrm{Fe}$ & $0.0-0.7$ \\
\hline 7 & Titanium $\mathrm{Ti}$ & $0.0-0.15$ \\
\hline 8 & Chromium $\mathrm{Cr}$ & 0.1 \\
\hline
\end{tabular}

- A17075:

Aluminum Alloy 7075 is one of the highest strength alloys available. It has Good thermal Shock resisting capacity, good impact and fatigue strength. It Good Corrosive to resistant.

TABLE 4 CHEMICAL COMPOSITION OF AL7075
\begin{tabular}{|c|l|c|}
\hline No. & \multicolumn{1}{|c|}{ Material } & Composition \\
\hline 1 & Silicon $\mathrm{Si}$ & 0.40 \\
\hline 2 & Iron $\mathrm{Fe}$ & 0.50 \\
\hline 3 & Copper $\mathrm{Cu}$ & $1.2-2.0$ \\
\hline 4 & Manganese $\mathrm{Mn}$ & 0.30 \\
\hline 5 & Magnesium $\mathrm{Mg}$ & $2.1-2.9$ \\
\hline 6 & Chromium $\mathrm{Cr}$ & $0.18-0.28$ \\
\hline 7 & Zinc $\mathrm{Zn}$ & $5.1-6.1$ \\
\hline 8 & Titanium $\mathrm{Ti}$ & 0.20 \\
\hline
\end{tabular}

- S-GlassFiber:

$\mathrm{S}$-Glass is generally used for polymer matrix composites include, High production rates, improved mechanical properties compared to E-glass., High strength, High stiffness. Relatively low density, Non-flammable, Resistant to heat.

\begin{tabular}{|} 
TABLE 4 CHEMICAL COMPOSITION OF S-GLASS FIBER \\
\begin{tabular}{|c|l|c|}
\hline No. & \multicolumn{1}{|c|}{ Material } & Composition \\
\hline 1 & Silicon dioxide SiO2 & $65 \mathrm{wt} \%$ \\
\hline 2 & Aluminum Oxide $\mathrm{Al} 2 \mathrm{O} 3$ & $25 \mathrm{wt} \%$ \\
\hline 3 & Magnesium oxide $\mathrm{MgO}$ & $10 \mathrm{wt} \%$ \\
\hline
\end{tabular}
\end{tabular}

- CarbonFiber :

The use of this as the reinforcement material in polymer matrix composites is extremely common. Optimal strength properties are gained when straight, continuous fibers are aligned parallel in a single direction.

TABLE 4 CHEMICAL COMPOSITION OF CARBON FIBER

\begin{tabular}{|l|l|l|}
\hline No. & \multicolumn{1}{|c|}{ Material } & \multicolumn{1}{|c|}{ Composition } \\
\hline 1 & Silicon Oxide $\mathrm{SiO} 2$ & $54 \mathrm{wt} \%$ \\
\hline 2 & Aluminium Oxide $\mathrm{Al} 2 \mathrm{O} 3$ & $14 \mathrm{wt} \%$ \\
\hline 3 & $\begin{array}{l}\text { Calcium Oxide } \mathrm{CaO}+\text { Magnesium Oxide } \\
\text { MgO }\end{array}$ & $22 \mathrm{wt} \%$ \\
\hline 4 & Boron Oxide B2O3 & $10 \mathrm{wt} \%$ \\
\hline 5 & $\begin{array}{l}\text { Sodium Oxide Na2O + Potassium Oxide } \\
\text { K2O }\end{array}$ & $2 \mathrm{wt} \%$ \\
\hline
\end{tabular}


TABLE 5 PROPERTIES OF MATRIX COMPOSITES

\begin{tabular}{|c|c|c|c|c|}
\hline Parameter & AL6061 & AL7075 & Carbon & S-glass \\
\hline$\sigma_{\mathrm{sy}}(\mathrm{MPa})$ & 310 & 560 & 1100 & 4587 \\
\hline$\sigma_{\mathrm{yt}}(\mathrm{MPa})$ & 270 & 207 & 900 & 3250 \\
\hline $\mathrm{E}(\mathrm{MPa})$ & $69 \mathrm{e}^{3}$ & $1.93 \mathrm{e}^{5}$ & $0.5 \mathrm{e}^{3}$ & $8.69 \mathrm{e}^{5}$ \\
\hline$\mu$ & 0.33 & 0.31 & 0.25 & 0.28 \\
\hline $\mathrm{p}\left(\mathrm{kg} / \mathrm{m}^{3}\right)$ & 2700 & 3000 & 1600 & 2480 \\
\hline
\end{tabular}

- Loading Conditions :

Load in $\mathrm{Kg}(\mathrm{W})=2 \mathrm{~kg}$

The Load has been considered just to verify the suitability of trials on the different composite materials. The Composites are lighter in weight hence considering the same point the load has been considered.[3]

Hence Normal Force can be said as,

Normal Force $\left(\mathrm{F}_{\mathrm{N}}\right)=19.62 \mathrm{~N}$

Disc Rotation $(\mathrm{N})=1000 \mathrm{Rpm}$.

The Speed of the disc has been selected on the basis of regular speed of engine clutch. The Regular speed is about 1000-2000 $\mathrm{Rpm}$. The Engagement speed is $2000 \mathrm{Rpm}$ hence to ensure the safety, 1000 Rpm speed has been considered.[4]

Sliding Velocity:

The Sliding Velocity can been given as ,

$\mathrm{V}_{\mathrm{S}}=\left(\pi \mathrm{D}_{\mathrm{s}} \mathrm{N}\right) /(60 * 1000)$

Where.

Ds $=$ Sliding phase diameter $=100 \mathrm{~mm}$

Hence,

$\mathrm{V}_{\mathrm{S}}=5.23 \mathrm{~m} / \mathrm{s}$

- Experimental Calculations :

1. Volume loss (V): The volume loss is actually the remaining material of pin which is left after the worn out of the pin. The Volume is the loss material of the pin which can be mathematically given as,[7]

Volume loss $=$ Cross sectional Area $\times$ Height loss $\mathrm{V}=\mathrm{A} / \mathrm{H}_{2} \quad \mathrm{~mm}^{3}$

2. Wear rate: The wear rate per unit sliding distance in the transient wear regime decreases until it has reached a constant value in the steady-state wear regime. Hence the standard wear coefficient value obtained from a volume loss versus distance curve is a function of the sliding distance.[7]

Wear rate $=$ Volume loss $/$ Sliding distance $\mathrm{mm}^{3} / \mathrm{Nm}$

3. Wear resistance: When material generally offer good resistance to sliding and impact abrasion, increases the hardness and toughness of the steel, making it an ideal material for applications that require high impact or high abrasion resistance.[7]

$$
\text { Wear resistance }=1 / \text { Wear rate }
$$

4. Specific wear rate: At each loading condition, the wear rate is different. Hence the wear rate at particular loading condition is called as the Specific Wear rate. In can be defined as the ratio of wear rate to acting load. It can be given as,[7]

Specific wear rate $=$ Wear rate/load

5.Coefficient Of Friction: The coefficient of friction is ratio of frictional force to normal load.[7]
$\mu=\mathrm{F} / \mathrm{FN}$

\section{- Experimental Process :}

Clean and dry specimen and disc using solvent. Weight Specimen and disc individually on weighing scale having accuracy $0.1 \mathrm{mg}$.Insert disc on fixture and tightens screws from sides to clamp, ensure the perpendicularity within +1 dig to the axis of rotation. Insert Specimen to jaw holder,insure it is sitting properly and tighten two jaws to hold ball and tighten jaws to specimen holder .Switch on controller, allow $5 \mathrm{~min}$ for normalizing the display on controller. Press test start push button on controller after setting 10 min time on timer display, rotate speed knob till 60 $\mathrm{rpm}$ is displayed, ensure the speed is constant at 60 , then press stop button.Press zero button of normal load,

frictional force and wear on controller.Open software on pc, select a new file, enter test parameters and sample id on screen and click on start icon to activate screen to receive data. Add $2 \mathrm{~kg}$ dead weight on loading pan to apply normal load .Set timer to $30 \mathrm{~min}$ to achieve $1000 \mathrm{mt}$ sliding distance. Begin test by pressing on start push button, record the room temperature and relative humidity. Test stop after completion of test duration. Remove specimens, clean off loose wear debris, note the existence of feature on or near thee wear scar such as ;protrusions , displaced metal, discolorations, micro cracking or spotting Weight the specimen and record the loss in weight .The loss in weight is negligible, alternately volume loss may be measured On the bottom disc no wear is observed
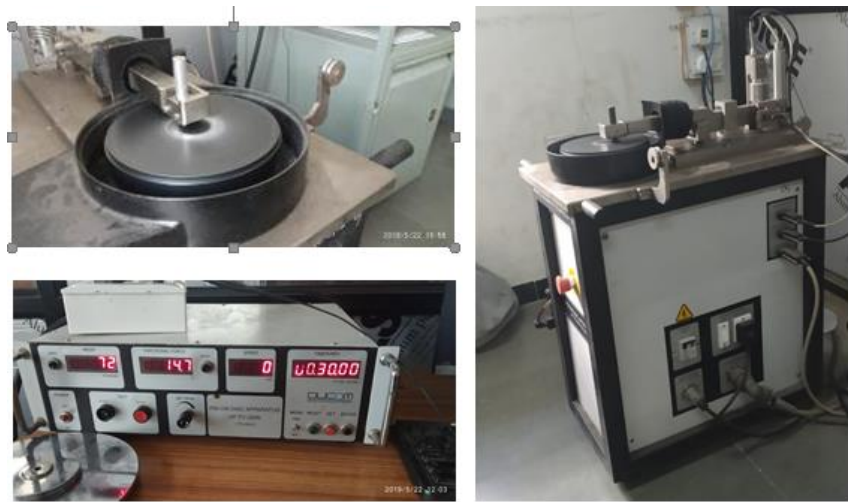

Figure 4: Experimental Process

Normal Load

$=2 \mathrm{~kg}=19.62 \mathrm{~N}$

Time Interval 


\section{RESULTS AND DISCUSSION}

3.1 Wear Volume :

Wear Volume is the volume which is lost by the material after rubbing of pin. This is actual weight lost by the material.[14]

Wear Volume canbe determined as by,

$\mathrm{V}_{\mathrm{w}}=\left(\mathrm{W}_{1}-\mathrm{W}_{2}\right) /$ Density

Hence for all the materials, wear can be determined as,

So as to determine the volume rate in $\mathrm{mm}^{3}$, the densities of materials are converted to $\mathrm{g} / \mathrm{mm}^{3}$.

Hence forth the wear volume can be seen as follows,

TABLE 12

CALCULATION FOR WEAR VOLUME

\begin{tabular}{lccc}
\hline Material & $\begin{array}{c}\text { Initial Weight } \\
\mathbf{W}_{\mathbf{1}}(\mathbf{g m})\end{array}$ & $\begin{array}{c}\text { Final Weight } \\
\mathbf{W}_{\mathbf{2}} \\
\mathbf{( g m )}\end{array}$ & $\begin{array}{c}\text { Wear } \\
\text { Volume } \\
\left(\mathbf{m m}^{\mathbf{3}}\right)\end{array}$ \\
\hline Al6061 & 19.62 & 18.97 & 240.7407 \\
AL7075 & 18.64 & 17.23 & 470 \\
Carbon Fiber & 10.22 & 10.10 & 95 \\
S-Glass & 10.91 & 10.80 & 45.83333 \\
\hline
\end{tabular}

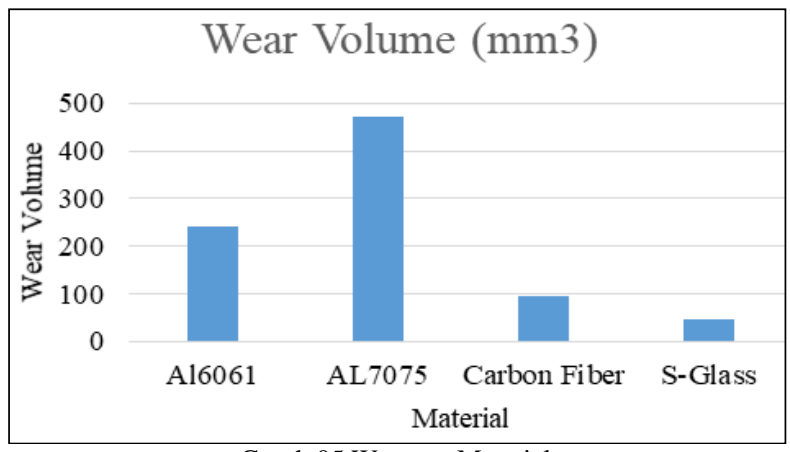

Graph 05 Wear vs. Material

The wear Volume for Carbon Fiber and S-Glass Fiber are comparatively low. Due their low density and good wear resistant property, the gives less wear out during the experimental test.

\subsection{Co-Efficient of Friction :}

The Graph 05, shows the behavior of co-efficient of friction for different materials under different interval of time. The Carbon fiber which shows the lower wear rate possess the coefficient of friction which slightly varies with respect to deeper wear testing. The Friction coefficient for S-Glass Fiber remains constant throughout the test, which shows that the wear behavior will remain constant after a certain period of time. The aluminum composites of 6061 shows the lowest amount of friction rate whereas the friction co-efficient of 7075 decreases with respect to time. After an interval of time, the Friction co-efficient of 7075 continuous to be constant.[14]

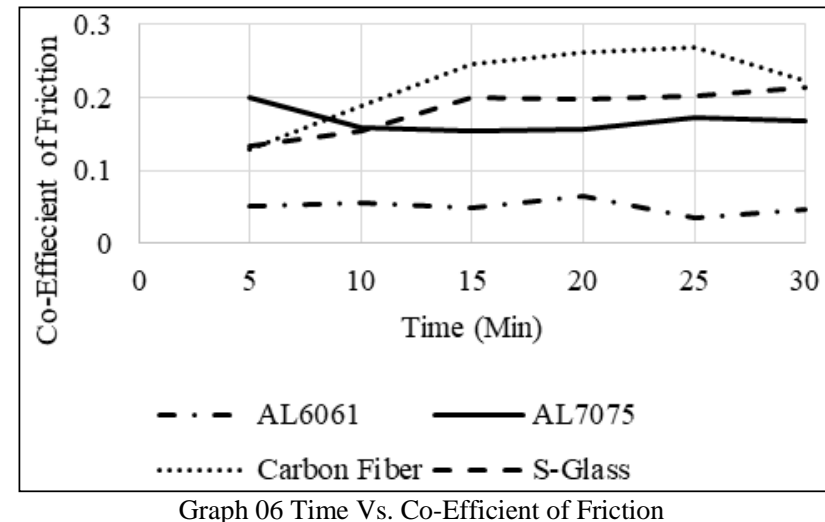

From the experimentation results, it is clear that the polymer matrix composites shows better results as that of Aluminum Composites. The Aluminum Composites, also show better results. The Aluminum and polymer composites can be used as replacement for other friction lining materials so as to reduce the wear rate and also to increase the life of friction pads in case of clutch plates.

\subsection{Hardness Analysis}

The wear system is very important; the presence of corrosion or impact can have large influence on the relation between hardness and wear resistance. The relation between hardness and wear is actually inversely proportional. The Harder the material goes, the less the wear volume.[14]

TABLE 13

HARNDESS ANALYSIS OF MATERIAL

\begin{tabular}{|c|c|c|}
\hline No. & Material & HardnessSh.D \\
\hline 1 & AL6061 & 81.8 \\
\hline 2 & AL7075 & 82.9 \\
\hline 3 & S-Glass Fiber & 92 \\
\hline 5 & Carbon Fiber & 95 \\
\hline
\end{tabular}

Hence from the table above, S-glass Fiber has highest amount of hardness amongst all and so the wear rate of S-glass fiber is less. So on if Aluminum composites are considered, it possess less hardness and hence the wear rate of aluminum composites are high.

\subsection{Discussions :}

- As per the experimentation, the wear rate of Carbon fiber and S-glass Fiber are the least. As well as the Aluminum composites are also up to better performance.

- The Wear Volume for Carbon fiber is validated for experimentation as well as the simulation.

- From experimentation as well as simulation, the difference in the results obtained are about $8 \%$.

- Simulation always shows the results without considering any of the losses, hence it shows the theoretical results.

- The Experimentation knows the practical disabilities and hence shows the practical-actual results considering all the losses 


\section{SIMULATION APPROACH}

a). Finite Element Analysis :

Simulation approach consists of considering the same test in Analysis software. For the Same Purpose, Ansys Version 18.1 is used. The analysis is done on Carbon Fiber Pin which is Rub on plate of Grey Cast Iron.

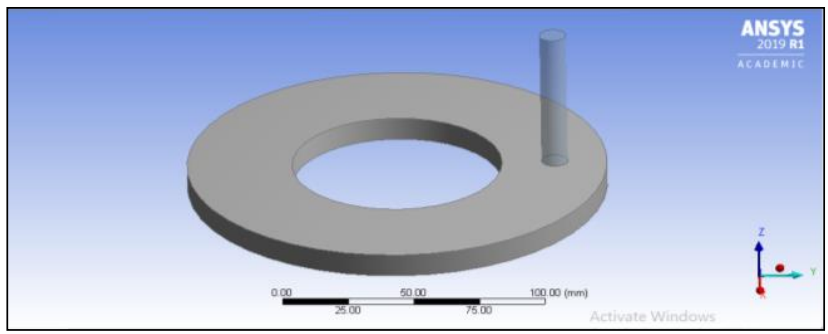

Figure 5 Pin on Disk Setup Created in Ansys Design Moduler

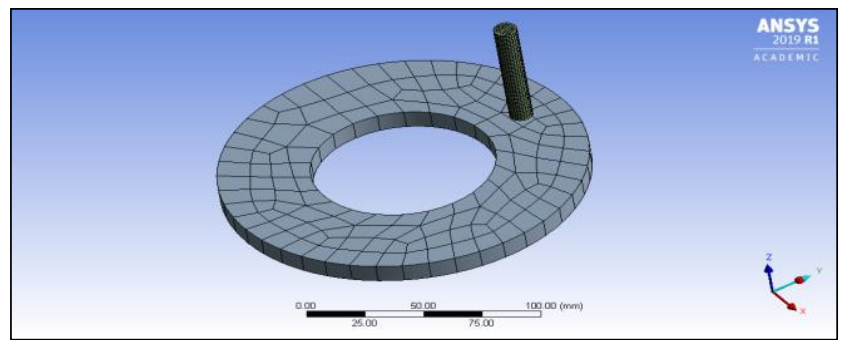

Figure 6Fine Mesh Setting

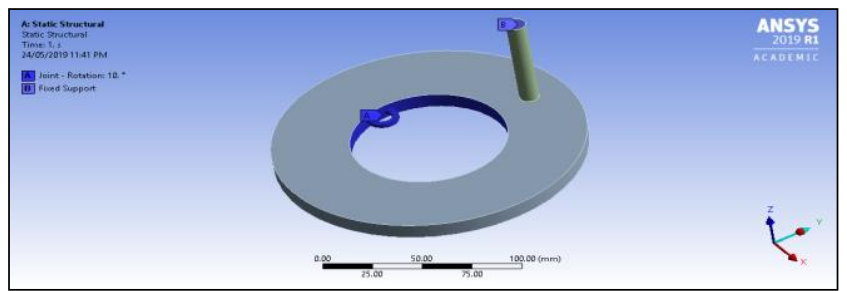

Figure 7Pre Analysis Setting

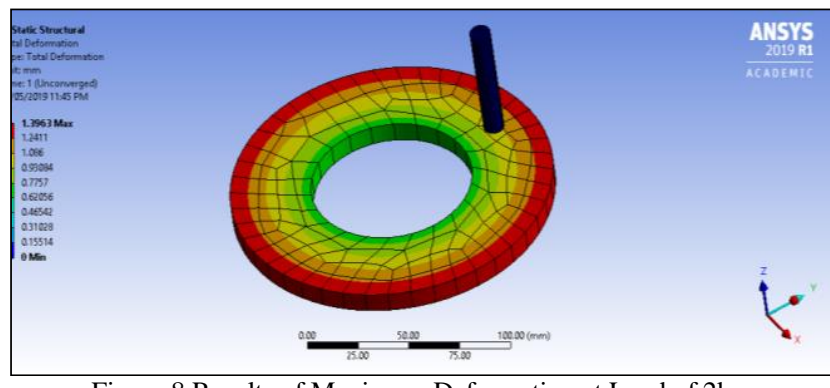

Figure 8 Results of Maximum Deformation at Load of $2 \mathrm{~kg}$

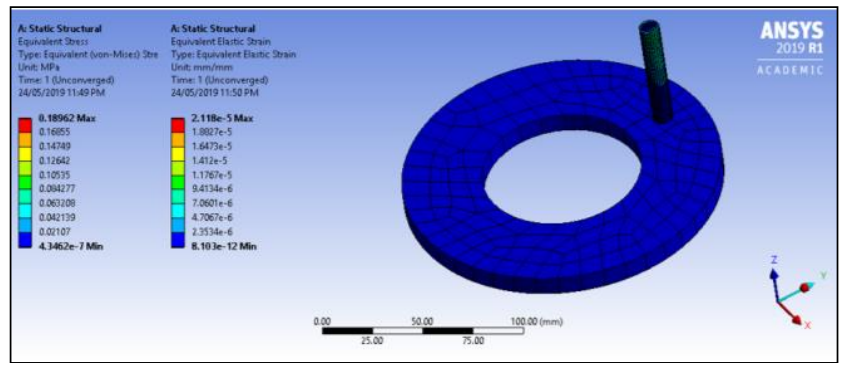

Figure 9 Results of Maximum Stress and Strain Produced at Load of $2 \mathrm{~kg}$ b). Validation with Experimental Results :

According to Simulation,

The Deformation in the Length of Pin is $1.39 \mathrm{~mm}$.

Consider it as,

Deformed Length, $\mathrm{L}_{\mathrm{d}}=1.39 \mathrm{~mm}$

Diameter of Pin, $\mathrm{d}=10 \mathrm{~mm}$

In such case, the Deformed Volume which is also the wear volume can be calculated as,

$\mathrm{V}_{\mathrm{w}}=(\pi / 4) \times \mathrm{d}^{2} \times \mathrm{L}_{\mathrm{d}}$

Henceaccording to Simulation, the wear volume can be stated as,

$V_{w}=109.115 \mathbf{m m}^{3}$

\section{CONCLUSIONS}

In the present work the investigations of wear and friction characteristics of aluminum matrix and polymer matrix material for clutch plate is carried out on pin on disk apparatus under different testing conditions.

It is observed that AL6061 shows very less coefficient of friction but wear volume is very high. As per requirement of clutch plate material S glass fiber shows significantly higher coefficient of friction i.e. about 0.2 and also it shows very less wear volume ie. $45 \mathrm{~mm}^{3}$ compared to aluminum matrix. So it can be concluded that $\mathrm{S}$ Glass fiber can be used for clutch plate material.

\section{ACKNOWLEDGMENT}

The report is outcome of guidance, moral support and devotion bestowed on me throughout my work. For this I acknowledge and express my profound sense of gratitude and thanks to everybody who have been a source of inspiration during the experimentation. The consistent guidance and support provided by Dr A.B Kakade thankfully acknowledged and appreciated for the key role played by him in providing me with his precious ideas, suggestions, help and moral support that enabled me in shaping the experimental work.

\section{REFERENCES}

[1] QianZouet.al., "Investigation of surface characteristics and tribological behavior of clutch plate materials", Elsevier Publication, Wear 302 2013.

[2] AravindVadiraj "Engagement characteristics of a friction pad for commercial vehicle clutch system", Indian Academy of Sciences, Vol. 35, Part 5, pp. 585-595, October 2010.

[3] A. Mr. Dattatray B. Jondhale, B. Prof. Vishnu S. Aher, "Experimenta Evaluation of Clutch Plate Material by Tribological Properties Using Trobometer," International Engineering Research Journal.

[4] Miss Kaveri. S. Kadam, "Tribological Investigation of Ferodo Lining Material Embedded with Copper and SiC particles For Clutch plate" International Engineering Research Journal Page No 1810-1816.

[5] G.Kannan, K.Krishnamoorthy, K.Loheswaran, "Review on Different Materials Utilized in Clutch Plate," South Asian Journal of Engineering and Technology Vol.2, No.23, Pg. 135 - 142 ,2016.

[6] S. Gouseseema begum, A. Balaraju, "Design and Analysis of Friction Clutch Plate using Ansys", International Journal of Advanced Engineering Research and Science (IJAERS), Vol-2, Issue-5, May2015

[7] Virendrakumarpatel et.al. ."Review on Wear Analysis of Differen Types of Clutch Material," International Journal of Research in Advent Technology, Vol.3, No.11, November 2015. 
[8] Ravikiran M. Tate, "Design and Analysis of Clutch Plate for Automatic Single Plate Clutch", IJSRD - International Journal for Scientific Research \& Development, Vol. 3, Issue 09, 2015.

[9] B. Nivas et.al. "Design and Analysis of Clutch Plate Using Steel Material [En - Gjs-400 -15steel]", IOSR Journal of Dental and Medical Sciences (IOSR-JDMS), Volume 13, Issue 5, PP 76-78, May. 2014.

[10] J Joy Mathavan and Amar Patnaik, "Analysis of wear properties of aluminium based journal bearing alloys with and without lubrication", IOP Conf. Series: Materials Science and Engineering, 2016.

[11] Sandip B. Chaudhari et.al. "Wear Analysis of Polytetrafluoroethylene (PTFE) and it's Composites under Wet Conditions", IOSR Journal of Mechanical and Civil Engineering (IOSR-JMCE), Volume 8, Issue 2,Pg 07-18 Jul. - Aug. 2013.

[12] K.C.Lathiya, et.al. "A Literature Review on Failure in Single Plate Clutch System", IJSRD - International Journal for Scientific Research \& Development, Vol. 2, Issue 10, 2014.

[13] Mamta G. Pawar, Monarch K. Warambhe, Gautam R. Jodh, "Design and Analysis of Clutch Using Sintered Iron as a Friction Material, International Journal of Innovative Technology and Exploring Engineering (IJITEE), Volume-3, Issue-7, December 2013.

[14] Zeyaullah Ansari, "Investigation of Stresses of Friction Clutch Plate on Different Material, International Journal of Innovative Research in Science, Engineering and Technology, Vol. 6, Issue 3, March 2017.

[15] N. A. Barve, "Analysis of Single Plate Friction Clutch Using Finite Element Method", International journal of advance scientific research and engineering trends, Volume 2, Issue 11, JUNE 2017.

[16] P. Anusha Lakshmi, "Design and Material Optimization of Mahindra XYLO E6 Clutch", International Journal of Advanced Technology and Innovative Research, Vol.09, Issue.07, Pages: 1040-1045, June-2017.

[17] Avital Gabriel de Almeida Rosaa, JéfersonAparecidoMoreto, "Study on Friction and Wear Behavior of SAE 1045 steel, reinforced Nylon 6.6 and NBR Rubber Used in Clutch Disks" Journal of Materials Research, Volume 17(6), Page 1397-1403, 2014.

[18] T. Vijayarajet.al., "Design and structural Analysis of Conventional Clutch and flywheel Assembly", International Journal of Advance Research and Innovative Ideas in Engineering, Vol-3 Issue-5 2017. 